\title{
Nociception monitoring tools using autonomic tone changes for intraoperative analgesic guidance in pediatric patients
}

\section{Byung Gun Lim}

Received September 30, 2019

Accepted September 30, 2019

\section{Corresponding author}

Byung Gun Lim, M.D., Ph.D.

Department of Anesthesiology and

Pain Medicine, Korea University Guro

Hospital, Korea University College of

Medicine, 148 Gurodong-ro, Guro-

gu, Seoul 08308, Korea

Tel: 82-2-2626-3231

Fax: 82-2-2626-1438

E-mail: bglim9205@korea.ac.kr

\section{ORCID}

https://orcid.org/0000-0002-3302-1831
Department of Anesthesiology and Pain Medicine, Korea University College of Medicine, Seoul, Korea
Nociception monitoring devices using changes in autonomic nervous system activity have been developed in numerous ways. Although there have been few studies conducted on children, compared to the relatively higher number of studies on adults, most of the nociception monitors in children, as in adults, appear to be more useful than the standard clinical practice that uses hemodynamic parameters in the evaluation and treatment of intraoperative nociception (pain) during general anesthesia. Particularly, when monitoring the surgical pleth index (SPI) in anesthetized children, the application of a new target range of SPI values $(\leq 40)$ to the SPI monitoring criteria seems to be necessary for providing a more proper intraoperative analgesia. The analgesia nociception index (ANI) shows promising results in anesthetized adults, and recently, positive results along with cardiorespiratory coherence have been reported in pediatric patients. Newborn infant parasympathetic evaluation (NIPE) could be useful for providing adequate analgesia in newborns, infants, and children under 2 years of age in anesthetized or awake states. In cases of skin conductance and pupillometry, further studies are needed. Understanding the pros, cons, and limitations of these nociception monitoring tools will provide more effective and safe intraoperative analgesia to pediatric patients undergoing general anesthesia, and it may also help to plan and conduct promising research on the use of perioperative nociception monitoring in pediatric patients in the future.

Keywords: Analgesia; Anesthesia, general; Autonomic nervous system; Children; Monitoring, intraoperative; Nociception test; Pain measurement.

\section{INTRODUCTION}

It is exceedingly difficult to detect the pain occurring during surgery under general anesthesia accurately and to perform appropriate pain control, and the level of analgesia provided during the operation is fundamental, because it is directly linked to postoperative pain and complications. This is especially important for pediatric patients, because it is more challenging to communicate with them than adults during the perioperative period. Moreover, postoperative emergence and recovery patterns of pediatric patients are different from those of adults, and it is also difficult to predict the degree of postoperative pain (due to a limitation of pain rating scales). Therefore, if the degree of nociception (pain) during surgery is objectively predicted and evaluated, thereby appropriately controlled in such pediatric patients, postoperative pain can be effectively reduced, and it may be helpful to perform additional analgesia for residual pain and to prevent postoperative complications.

In addition, while regional anesthesia (analgesia) can be performed in an arousal state in adults and the evaluation of its effectiveness (success or failure) is possible, it is exceed-

This is an Open Access article distributed under the terms of the Creative Commons Attribution Non-Commercial License (http://creativecommons.org/licenses/by-nc/4.0) which permits unrestricted non-commercial use, distribution, and reproduction in any medium, provided the original work is properly cited. 
ingly difficult to perform the procedure in an arousal state in pediatric patients. In this case, the evaluation of the success of regional analgesia becomes more difficult because the procedure is performed during general anesthesia. If there is a nociception monitoring device that can appropriately evaluate the effect of local anesthetics administered for regional analgesia, by monitoring before and after regional analgesia, it is possible to evaluate the effectiveness of regional analgesia and to judge its success. In this respect, intraoperative nociception monitoring can be beneficial for perioperative pain management in pediatric patients.

During the last two decades, several nociception monitoring tools have been developed, which utilize physiological markers that are useful for performing objective pain assessments. Of these, the most common method is to measure the degree of pain by measuring changes in the autonomic nervous system (ANS) activity [1]. Depending on which ANS surrogate marker-including pulse wave amplitude and pulse beat interval, heart rate variability, skin sweating, and pupillary changes-is used by each device, the basic operating principles and characteristics of the device (surgical pleth index, analgesia nociception index, heart rate variability, skin conductance, or pupillometry etc.) are determined. This article reviews the efficacy, reliability, and limitations of the devices for intraoperative analgesia in pediatric patients undergoing general anesthesia by analyzing the results of the studies on the nociception monitoring devices for pediatric patients reported so far-even though the results are fewer than those for adults [2]. A better understanding of the nature of these devices may help provide more effective and safe perioperative analgesia to pediatric patients undergoing surgeries using general anesthesia.

\section{LITERATURE SEARCH STRATEGIES AND RESULTS}

A literature search for the review was performed on major international and South Korean databases (PubMed, Embase, Cochrane, Web of Science, Scopus, and KoreaMed) to identify articles including systematic reviews, meta-analyses, practice guidelines, narrative reviews and clinical trials published since 1990 that assessed nociception or pain using nociception monitoring tools or indices for analgesic guidance in pediatric patients undergoing surgery using anes- thesia. Databases were searched with the strings made using the Medical Subject Headings (MeSH) and free text terms (Analgesia; Anesthesia, general; Autonomic nervous system; Children; Monitoring, intraoperative; Nociception test; Pain measurement etc.). After the initial electronic search, the author evaluated the bibliographies of the identified studies and performed a manual search using Google Scholar. The articles identified were assessed individually for inclusion in the analysis.

Searches of the databases yielded 1,010 articles (Fig. 1). Of these, 950 publications were excluded, because it was clear from the title and abstract that they did not fulfill the selection criteria. From the remaining 60 articles, 30 potentially relevant studies were identified by scrutinizing the full-text articles. Thirty other publications were excluded because they included adult patients, or did not include available interventions (pain measurement with nociception monitoring tools or indices using autonomic tone changes in pediatric patients undergoing surgery under anesthesia). Therefore, 30 studies were finally included in this review (Fig. 1).

\section{ANS MARKERS FOR NOCICEPTION ASSESSMENT}

Postoperative pain increases ANS activity (i.e., increases sympathetic nervous system activity and postoperative analgesia suppresses the response) [3-5]. Similarly, nociception caused by surgical stimulation during general anesthesia causes the release of stress hormones, and the level of stress hormone release depends on the level of analgesia provided $[6,7]$. This is because there is a neuroanatomic overlap between the pain transmission path and the ANS pathway [8]; these rationale and findings have led to the assumption that pain causes a change in ANS activity, which has resulted in the development of several monitoring devices using ANS surrogate markers for objective pain assessment. Derived cardiovascular and respiratory parameters including pulse wave amplitude, pulse beat interval, heart rate variability, the pattern of blood pressure, and heart rate responses are representative ANS surrogate markers [1]. In addition, sweating and pupillary changes are also used as ANS markers for nociception monitoring [1].

Although studies on various nociception monitoring devices have been conducted on adults, recent research results 


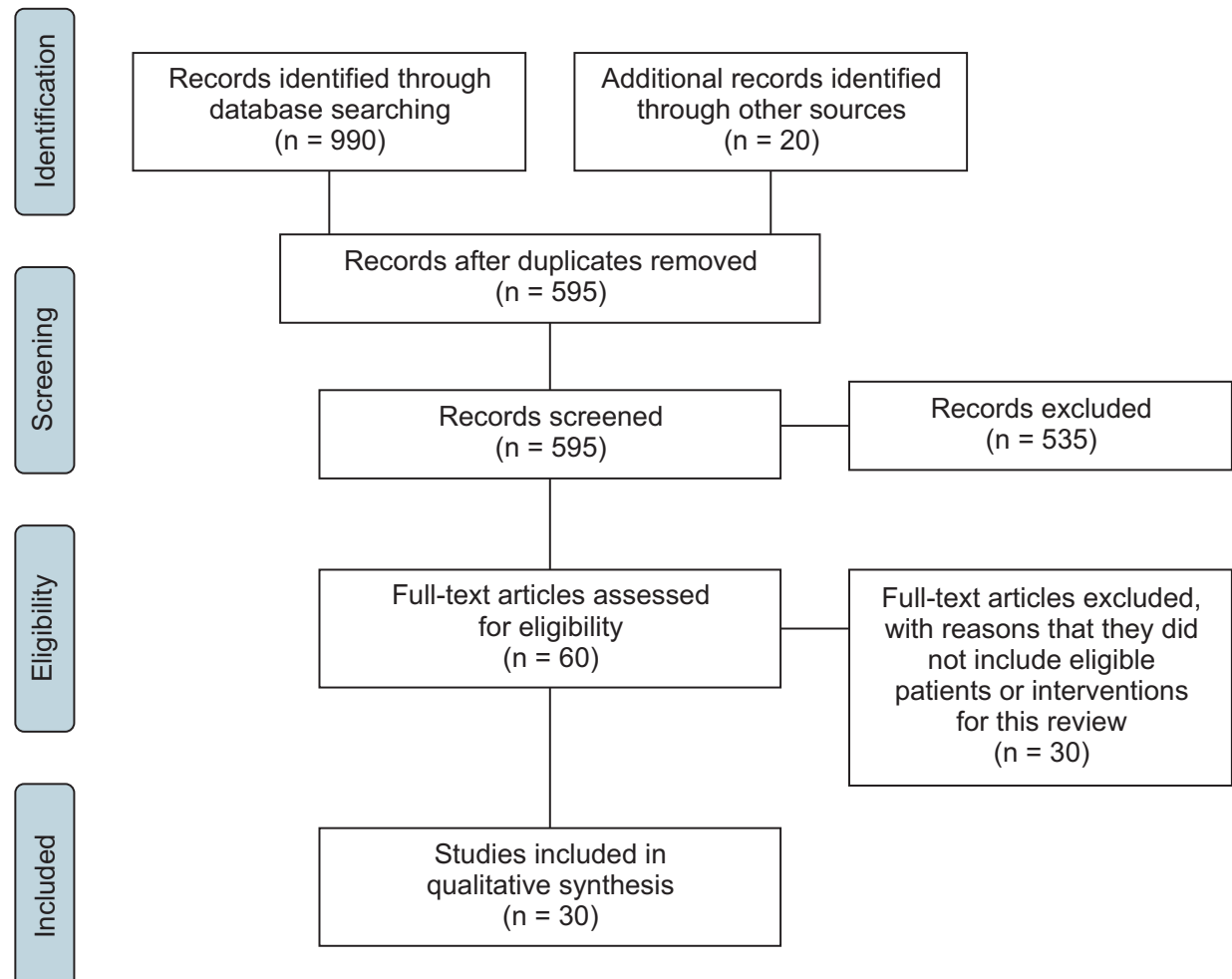

Fig. 1. Flow diagram for article search and inclusion criteria in the review.

on pediatric patients have also been reported. It is essential to understand the efficacy and limitations of the nociception monitoring tools in pediatric patients undergoing general anesthesia by analyzing existing literature and research results, especially to recognize the differences between the pediatric and adult results, in order to appropriately provide intraoperative analgesia based on these monitoring devices. Therefore, in addition to the 30 pediatric studies included in this study, the representative studies performed by applying the nociception monitoring tools used in the pediatric studies to adults were also cited and compared in this review.

\section{NOCICEPTION MONITORING TOOLS USING PULSE WAVE AMPLITUDE AND PULSE BEAT INTERVAL}

\section{Surgical pleth index (SPI)}

SPI, also called the Surgical Plethysmographic Index or Surgical Stress Index, is a simple, non-invasive monitoring tool used to assess nociception during anesthesia by analyzing the waveform and heartbeat of photoplethysmography in pulse oximeters. SPI is calculated using the pulse photoplethysmographic amplitude (PPGA) and heartbeat interval
(HBI), which are measurable in the photoplethysmography [9] as follows in this equation,

$$
\mathrm{SPI}=100-(0.67 \times \mathrm{PPGA}+0.33 \times \mathrm{HBI})
$$

SPI values range from 0 (no stress) to 100 (maximum stress level), and in previous studies, an SPI range of 20-50 usually indicates adequate analgesia during surgery under general anesthesia [10-13]. It is also recommended to keep SPI values below 50 and avoid rapid increases (more than 10-point increase over a short time) as another criterion to maintain adequate analgesia [14].

The effectiveness of SPI as a tool for monitoring and evaluating nociception and administering analgesics in adults was demonstrated in several studies [10-13,15]. Notably, they have shown that SPI-guided analgesia offers several clinical benefits in comparison to analgesia based on conventional hemodynamic parameters during surgery under general anesthesia $[10,12,13,16,17]$. In contrast, limitations have been reported for various clinical situations and confounding factors [18-23], one of which may be age. Thus, limitations presented in the studies of pediatric patients must be considered carefully $[19,24,25]$.

Although the number of studies related to SPI in children 
is limited, efforts to reduce the incidence of postoperative pain and complications by appropriately evaluating nociception during surgery and performing appropriate analgesia have been attempted in various forms. The results have been reported in several ways, also [19,24-26]. Harju et al. [26] observed changes in intraoperative SPI in two groups receiving ultrasound-guided ilioinguinal and iliohypogastric nerve block with saline or ropivacaine before the beginning of surgery after anesthesia induction in patients under 24 months old undergoing inguinal hernia surgery. As a result, an increase in SPI was observed in both groups after endotracheal intubation, whereas an increase in SPI during surgical incision was observed only in the saline-injected group. Harju et al. [26] reported that the reactivity of SPI to surgical stimuli was blunted in the ropivacaine-injected group, suggesting that SPI monitoring may be useful for determining the analgesic effect of the nerve block in pediatric patients undergoing regional analgesia, but also reported that the reactivity of the SPI was rather small, and there was a limitation of marked inter-individual variability in SPI reactions to nociception. More importantly, several other pediatric studies about SPI have shown that children have less confidence in SPI than adults, and thus children should receive intraoperative analgesia based on SPI levels that differ from those of adults. Supporting this, Park et al. [19] found that the cardiovascular structure and function of children-especially the vascular distensibility-is different from adults and that the actual nociception levels in children are not reflected in SPI values and the pediatric SPI value tends to be lower during surgery. A possible explanation is that ultrasonographic examinations of vascular structures showed lower vascular wall stress and higher distensibility in children than in adolescents [27], and basal catecholamine concentrations and resting muscle sympathetic nerve activity are also lower in children than in adults [28]. Due to these characteristics, the stimulation of vascular smooth muscle and vascular contractile force that occur during the activation of the sympathetic nervous system may be less in children. Two factors determine SPI values, HBI and PPGA, of which PPGA depends on the vascular wall distensibility and intravascular pulse pressure [29] and has double the effect on SPI values compared to HBI (Equation 1). Because children have lower vascular contractility and higher vascular distensibility than adults, activation of the sympathetic nervous system due to nociception is unlikely to significantly reduce PPGA as in adults, which can result in underestimation of SPI values.

The notion that there is less reduction in PPGA in children than in adults due to the unique characteristics of children's vascular response at the time of nociception is supported by comparing the SPI data of previous studies. Compared with the results of two studies that reported changes in SPI, heart rate (HR), and PPGA during endotracheal intubation after administration of $2 \mu \mathrm{g} / \mathrm{kg}$ of fentanyl for anesthesia induction $[30,31]$, the change in SPI values (the amount of increase) after endotracheal intubation was relatively higher in the adult study [30], while the change in HR was similar. Therefore, it can be inferred that the amount of change in PPGA, that is, the amount of decrease in PPGA, would have been higher in adults. Indeed, the median difference for PPGA before and after intubation reported in the pediatric study [31] was small (-0.51). Fig. 2 schematically shows the data from these two studies and the changes which occur in the photoplethysmography in adults and children at the time of nociception, the difference between them, and how the SPI values are changed.

In summary, Park et al. [19] reported that for children undergoing tonsillectomy under general anesthesia, intraoperative fentanyl requirement was lower for the SPI-guided analgesia group than for hemodynamic parameters-based analgesia, but postoperative pain and emergence agitation scores and rescue fentanyl dose were higher in the SPI-guided analgesia group, and thus SPI values in children are less likely to accurately reflect the nociception-antinociception balance due to their unique cardiovascular structure and physiology. It was concluded that re-establishment of the target SPI range or the development of new formulas for children is necessary for proper intraoperative analgesia in children undergoing general anesthesia.

Ledowski et al. [24] also found that SPI cut-off values of 50, the most commonly used cut-off value in SPI-related studies, do not have clinically appropriate sensitivity or specificity to predict the presence of acute pain in the recovery room, and suggested that it may be more appropriate to adjust to a cutoff of 40 or lower (which is lower than the existing cut-off value of 50) to provide intraoperative analgesia that avoids moderate and severe postoperative pain in children. Ledowski et al. [24] reaffirmed that, in children, intraoperative analgesia during general anesthesia should be performed based on SPI 

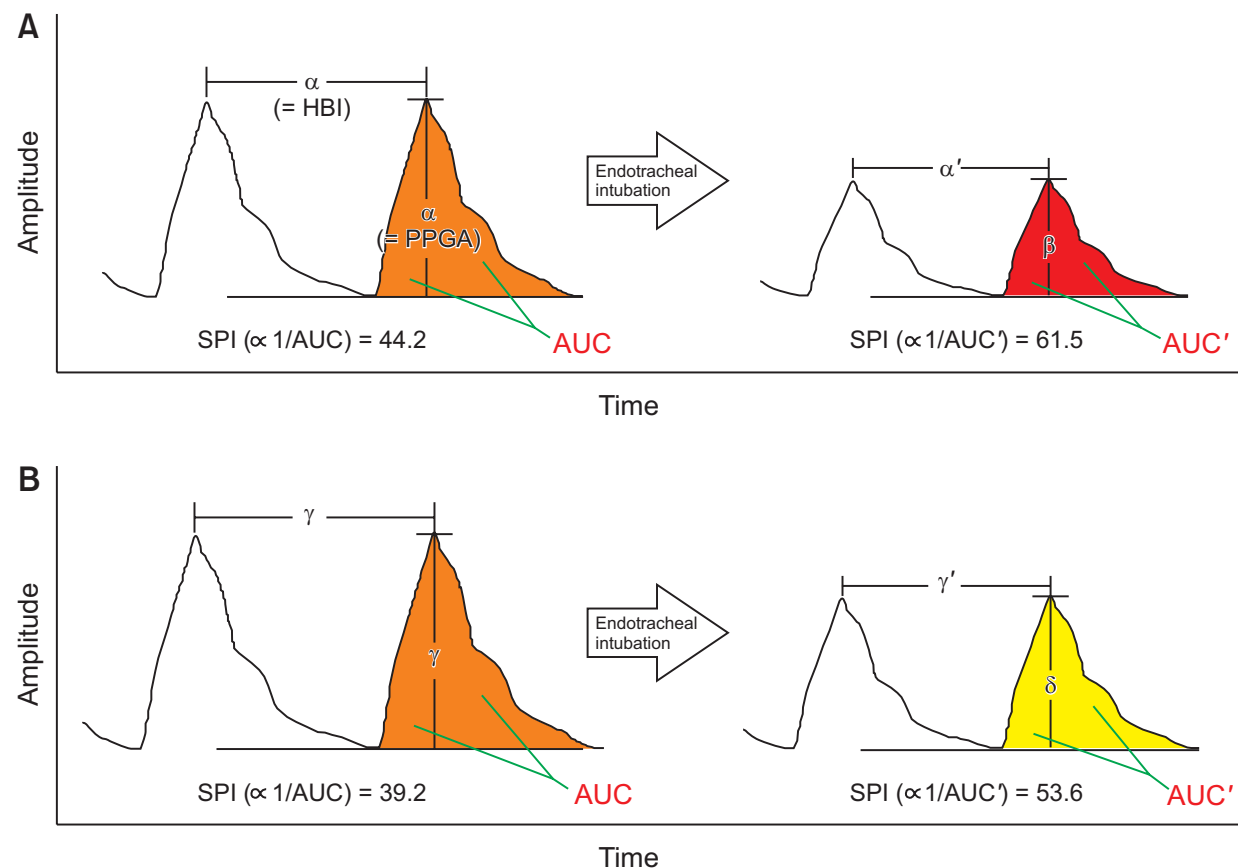

Fig. 2. Comparison of photoplethysmographic (PPG) responses between adults and children for nociception during anesthesia. The schematic diagram shows the difference between adults and children on the change of the PPG signal during endotracheal intubation at anesthesia induction. The changes (decrease) of the photoplethysmographic amplitude (PPGA) and area under the curve (AUC) are smaller in children, and the resulting changes (increase) of the surgical pleth index (SPI) values are also smaller in children (refer [SPI $\propto 1 / A U C]$ ). That is, this difference in PPG responses for nociception may cause a difference in SPI values between adults and children. (A) PPG waveforms in adults. With an assumption that heartbeat interval $(\mathrm{HBI})$ equals to PPGA $(\mathrm{HBI}=\mathrm{PPGA}=\alpha)$ and the data of SPI and heart rate in the reference (Mustola et al. Anesthesiol Res Pract 2010; 2010: 810721 [30]), the following equations can be established and thus the values of the variables can be assumed: $\alpha^{\prime}=\alpha-6.2=55.8-6.2=49.6 ; \beta$ $=\alpha-22.8=55.8-22.8=33.0$. (B) PPG waveforms in children. With an assumption that HBI equals to PPGA $(\mathrm{HBI}=\mathrm{PPGA}=\gamma)$ and the data of SPI and heart rate in the reference (Kallio et al. $\mathrm{Br}$ J Anaesth 2008; 101: 383-9 [31]), the following equations can be established and thus the values of the variables can be assumed: $\gamma^{\prime}=\gamma-8.2=60.8-8.2=52.6 ; \delta=\gamma-17.5=60.8-17.5=43.3$. This figure is newly drawn based on the data of the two studies $[30,31]$ that reported changes in SPI, heart rate, and PPGA during endotracheal intubation.

values that differ from those in adults.

Song et al. [25] also reported there was no significant difference in SPI changes during cranial pin fixation among the groups received sufentanil infusion at three different rates $(0.2,0.5$, and $0.8 \mu \mathrm{g} / \mathrm{kg} / \mathrm{h})$ in pediatric patients aged $2-12$ years who underwent cranial pinning under general anesthesia, suggesting that SPI may not be sensitive enough to monitor a level of nociception and analgesia in children.

A systematic review using meta-analysis of six randomized controlled trials, examining the efficacy and safety of SPIguided analgesia and conventional analgesia based on hemodynamic parameters (blood pressure and HR) and during surgery under general anesthesia, showed that SPI-based analgesia reduced intraoperative opioid requirement and shortened extubation time, and there was no difference in the degree of postoperative pain and the incidence of perioperative complications [32]. Based on these findings, the systematic review suggested that nociception monitoring and analgesic administration using SPI are more useful for providing proper analgesia under general anesthesia in various clinical situations. However, considering that the number of randomized controlled studies included in this study is few, and only one of the included studies is for children [19], and the results of other studies related to SPI in children are conflicting [24-26], further studies are needed to determine the efficacy of SPI for intraoperative analgesia, especially in children.

\section{NOCICEPTION MONITORING TOOLS USING HEART RATE VARIABILITY}

\section{Heart rate variability (HRV)}

HRV refers to the degree of change (variability) in time and frequency analysis of the interval between successive 
heartbeats, which reflects the activity and balance of the autonomic nervous system, i.e., the interactions between the sympathetic and parasympathetic nervous systems. HRV monitoring devices calculate and measure HRV parameters such as standard deviations of normal RR intervals on standard electrocardiogram (time-domain analysis) or high-frequency (HF), low-frequency (LF), very low-frequency (VLF) power, and LF/HF ratio (frequency domain [power spectral density] analysis) quickly, easily, and non-invasively [33,34]. The LF/HF ratio is a quantitative measure of the overall balance between the sympathetic and parasympathetic nervous system and, when the ratio is high, indicates an increase in sympathetic activity or inhibition of parasympathetic activity.

HRV can be measured in both conscious patients and those under sedation or anesthesia [35-37], but similar to SPI, it can be affected by several physiological or psychological conditions such as age (typically decreasing with age) [38], drugs [39], psychological problems [40], comorbidities [41,42], depth of sedation or anesthesia $[43,44]$, and surgical stimuli [45]. Several clinical studies examining the correlation between the intensity of noxious stimuli such as surgical stimuli and corresponding HRV in anesthetized adult patients suggested that HRV could be used as an objective pain assessment tool $[46,47]$. In contrast, studies for HRV in unanesthetized adult patients showed conflicting results [48,49].

In addition, numerous studies have investigated the relationship between established behavioral indicators of pain and HRV at the evaluation of acute pain in pediatric patients, including preterm infants, newborn (neonate) infants, infants, and children in various clinical settings [50-52]. Consequently, HRV usually responded well to pain in most pediatric age groups, but the findings in infants were inconsistent [53]. On the other hand, physiological indicators (nociception monitoring devices), including HRV, are the only tools that can measure nociception in anesthetized younger children, but the results reported so far have limitations due to the nature of HRV, which is susceptible to several factors $[54,55]$.

Therefore, several real-time algorithms and indices using them have been developed to correct such confounding factors of HRV so that changes in HRV correspond well to the intensity of nociception. These algorithms and indexes include analgesia nociception index, cardiorespiratory coherence, and newborn infant parasympathetic evaluation (NIPE).

\section{Analgesia nociception index (ANI)}

ANI (MetroDoloris Medical Systems, France) combines electrocardiogram and respiratory rate with high-frequency adjustment $(0.15-0.4 \mathrm{~Hz})$ in the frequency domain analysis of HRV and shows parasympathetic activity in the numerical range of 0 (maximal pain) to 100 (no pain) (as opposed to SPI). Previous studies on ANI regarded ANI $\geq 50$ as appropriate analgesia and predicted that ANS responsiveness was caused by nociceptive stimulation when ANI < 30 [56,57].

The efficacy of ANI in intraoperative nociception monitoring and analgesia has been well documented through studies performed in adults $[56,58,59]$. Recent studies in pediatric patients also reported that ANI was more sensitive to detecting surgical stimuli during surgery and useful for monitoring intraoperative analgesia than other hemodynamic parameters [60-62].

Considering that ANI is shown to reflect not only intraoperative pain but also postoperative pain, that is, the degree of pain in conscious patients, it may have advantages over other pain monitoring devices $[63,64]$. Nevertheless, there are still studies that reported the opposite results $[57,65]$, much like the controversial issue of its reliability in conscious patients in the correlation between HRV and pain intensity $[48,49]$.

\section{Cardiorespiratory coherence}

Cardiorespiratory coherence, a non-invasive nociception monitoring device, measures a degree of ANS activity by analyzing the linear combination intensity between heart rate and respiration during general anesthesia and assesses the degree of pain in a range from 0 (low coherence, strong nociception) to 1 (high coherence, no nociception). It includes real-time cardiorespiratory coherence; cardiorespiratory coherence algorithm, or wavelet transform cardiorespiratory coherence algorithm. Although there are very few studies evaluating the efficacy of cardiorespiratory coherence to date, most of them have been conducted in children, and they reported notable outcomes that cardiorespiratory coherence is more sensitive and superior to hemodynamic parameters in detecting nociception, antinociception, and movement in pediatric patients undergoing general anesthesia [66-68]. 


\section{Newborn infant parasympathetic evaluation (NIPE)}

ANI was developed for HRV analysis in children over 2 years old and adults. Newborns, infants, and children under 2 years of age require a modified approach to HRV analysis because they have a lower HRV due to an immaturity of the ANS and high basal heart rate. The NIPE index (MetroDoloris Medical Systems), a modified form of ANI nociception monitoring, was developed for use in newborns (including premature infants) and children under 2 years of age [69]. The basic principle of NIPE is to analyze the parasympathetic activity of the ANS in real-time using HRV analysis. HRV signals above $0.15 \mathrm{~Hz}$ allow for automated HRV analysis of data indicative of parasympathetic nervous system activity via a high pass filter and exhibiting physiological respiratory sinus arrhythmia [69]. This automated analysis is quantified by the NIPE index, which ranges between 0-100 to reflect relative parasympathetic activity, with higher values indicating higher levels of parasympathetic activity. A NIPE index of less than 50 in newborns and infants under anesthesia usually suggests a presence of stress or nociception and insufficient analgesia [70].

NIPE does an excellent job reflecting a balance of nociception and antinociception. NIPE decreases in the presence of nociception in anesthetized infants and newborns, while increases in cases of loss of nociception or administration of analgesics [70,71]. In addition, Valencia-Ramos et al. [72] reported that NIPE monitoring reflected a change in the degree of comfort during nebulization for conscious infants with bronchitis in the intensive care unit. NIPE was suggested as a comfort monitoring system for infants. NIPE may also reflect psychological conditions such as psychological stability or discomfort and stress in conscious infants and newborns. Taken together, even if the evidence is still lacking, NIPE monitoring of nociception and analgesia, or discomfort and comfort in newborns and infants under two years of age under anesthesia or awareness may be more effective than other nociception monitoring modalities. However, Cremillieux et al. [73] reported that the NIPE index during painful procedures of premature infants in the neonatal intensive care unit did not reliably reflect acute pain. Thus, further research is required to study these issues.

\section{NOCICEPTION MONITORING TOOLS USING SKIN SWEATING}

\section{Skin conductance algesimeter (SCA)}

A SCA measures an increase in stress reflected in changes in the activity of the sympathetic nervous system. When the sympathetic nerves are activated, the plantar sweat glands in the palms and soles are filled with sweat. When the sweat reaches the skin, the skin resistance decreases, and the skin conduction increases, and when the sweat is reabsorbed, the skin conduction decreases again. When the skin nerves are activated by stimulation, both amplitude and frequency of efferent skin nerve bursts increase. Therefore, the increase in the number of skin conductance fluctuations (NSCF) and amplitude of skin conductance fluctuations in SCA measurements may be interpreted as increased activity of the sympathetic nervous system [74,75].

Unlike other nociception monitoring tools, the SCA index is not affected by circulatory changes, cardiac activity, vasoactive drugs, or neuromuscular blockade. Therefore, SCA is more sensitive and specifically associated with pain and noxious stimuli [76]. The SCA index responds quickly (in seconds) and allows continuous and objective monitoring with a wide range of indications in various clinical situations. It also has higher sensitivity and specificity in assessing pain than other monitoring devices currently available. SCA has been extensively studied, particularly in pediatric patients, for its efficacy and is known to be useful in assessing pain and analgesia. For premature infants, SCA is more sensitive and specific than behavioral-state observations in evaluating heel stick pain during blood sampling, tactile stimulation stress, and high decibel sound stimuli [77-79]. Both in healthy newborns and artificially ventilated infants, an increased NSCF on SCA monitoring correlated well with occurrences of pain and discomfort $[80,81]$.

Several studies evaluating the efficacy of SCA concerning general anesthesia in adult patients have shown that the SCA index is useful in monitoring perioperative stress with increasing values during nociceptive stimulation, such as endotracheal intubation and tetanic stimulation, and decreasing values during analgesic infusion $[82,83]$. Regarding postoperative pain, several studies have reported that the SCA index is well correlated with the numeric rating scale assessed by 
the recovery room $[84,85]$.

Few studies of SCA have been conducted on children under general anesthesia. Sabourdin et al. [61] reported that the responses of SCA to remifentanil at different infusion rates in children under general anesthesia was less sensitive than those of ANI. Therefore, despite many advantages of SCA, the evidence is still lacking in its efficacy for analgesia in pediatric patients undergoing general anesthesia. Thus further studies are required on these topics.

\section{NOCICEPTION MONITORING TOOLS USING PUPILLARY CHANGE}

\section{Pupillometry}

Pupillometry is based on the evaluation of the pupillary reflex dilatation induced by nociceptive stimulation. Pupillometry is a non-invasive monitoring technique which measures dynamic pupillary diameter by an infrared camera. Pupillary diameter increases in response to nociceptive stimulation.

The degree of pupillary dilatation in patients with anesthesia using propofol or inhalational anesthetics is associated with the intensity of nociceptive stimuli during operation. The pupillary reflex dilatation by nociception in pediatric patients was maintained during deep sedation with ketamine, and the degree of pupillary dilatation was related to the intensity of the nociceptive stimuli [86]. Therefore, pupillometry can be a useful nociception monitoring tool in pediatric patients sedated with ketamine. Additionally, it has been suggested that pupillometry is a useful nociception monitoring device by other studies in children and adolescents undergoing general anesthesia, which showed that nociceptive stimuli during anesthesia cause pupillary reflex dilatation, and administration of opioid analgesics or deep anesthesia (hypnosis) decreases the pupil diameter [87-89]. However, it must be considered that other factors such as severe anxiety [90] or drugs $[91,92]$ also influence the pupil diameter and reflex.

\section{REGIONAL ANALGESIA AND OPIOID CONSUMPTION DURING GENERAL ANESTHESIA}

Regional analgesia in pediatrics are performed after the induction of general anesthesia and before skin incision to reduce the surgical stress response and to spare intravenous opioid administration during surgery. The adequacy of regional analgesia in children has traditionally been assessed by monitoring changes in hemodynamic parameters caused by noxious stimuli. Inadequate regional analgesia is often defined as an increase in heart rate of about $10-20 \%$ or more from baseline within 1 to 2 minutes after surgical incision $[93,94]$. However, the use of these hemodynamic parameters to assess the effects of regional analgesia is not standardized and may be inaccurate [95-98]. Therefore, there have been attempts to perform a faster and more accurate evaluation and to minimize intravenous opioid requirements during surgery by determining the effects of regional analgesia using nociception monitoring devices that are proven effective in monitoring the nociception-antinociception balance during surgery.

As previously mentioned, Harju et al. [26] reported that no increase in SPI was observed during surgical incision, and the responsiveness of SPI to noxious stimuli was blunted in children undergoing ultrasound-guided ilioinguinal and iliohypogastric nerve block after anesthesia induction for inguinal hernia surgery, suggesting that SPI monitoring may be useful in discriminating the success of regional analgesia in pediatric patients. Song et al. [99] observed significant changes in some HRV parameters after performing a caudal block in pediatric patients undergoing urological surgery under general anesthesia. They concluded that these HRV changes indicated reduced sympathetic activity and increased heart rate predictability, suggesting that the assessment of the HRV parameters can be an indicator of a successful caudal block. Migeon et al. [93] assessed pupillary reflex dilatation and ANI monitoring to evaluate the adequacy of regional analgesia while performing a neuraxial or peripheral nerve block after anesthesia induction in pediatric patients undergoing urological and orthopedic surgeries under sevoflurane anesthesia. In patients with a failed nerve block, the pupil diameter increased significantly, and ANI decreased within $1 \mathrm{~min}$. Therefore, it was suggested that these two nociception monitoring tools would be helpful in rapidly and accurately discriminating the success of regional analgesia in pediatric patients. Meanwhile, in a prospective randomized trial performed by Dundar et al. [100], after performing a thoracic paravertebral block in adult patients undergoing breast surgery under general anesthesia, the rate of remifentanil infusion was adjusted 
based on ANI monitoring (maintained at 50-70) in an experimental group for further analgesia during surgery. As a result, it was reported that intraoperative remifentanil consumption in the experimental group based on ANI was significantly lower than that of the control group based on hemodynamic parameters, suggesting that ANI monitoring may help optimize opioid consumption during surgery in these clinical settings.

Comprehensively considering these findings, further studies are needed in pediatric patients with various regional analgesia and nociception monitoring devices in various clinical situations.

\section{CONCLUSIONS}

Nociception monitoring tools using ANS activity have been developed in several ways. Each monitoring device evaluates sympathetic or parasympathetic tone changed by nociception and the monitoring devices share being more effective than conventional hemodynamic parameters. At the same time, depending on which autonomic surrogate marker is used, the basic operating principle and characteristics of the monitoring device differ, and their usefulness in various clinical situations also differs. Therefore, a comprehensive analysis and understanding of these principles and study results are needed. This review analyzes the efficacy and limitations of several nociception monitoring devices, mainly focusing on the intraoperative analgesia in pediatric patients under general anesthesia and additionally comparing details about clinical conditions such as arousal state, postoperative pain, regional analgesia, and includes adult or younger children (newborn or infant) populations when needed.

Although most of the nociception monitoring devices still lack studies with pediatric patients, most nociception monitors in children (as in adults) appear to be more useful than the standard clinical practice that uses hemodynamic parameters in the evaluation and treatment of intraoperative nociception during general anesthesia.

Summarizing the characteristics of each monitoring device, SPI seems to be less valid and limited for children than for adults. It may be necessary to apply a lower target value range (maintained below 40) or to develop new formulas fitted to children to provide adequate analgesia during surgery under general anesthesia in children. ANI has shown promising results in anesthetized adults, and recently positive results along with cardiorespiratory coherence have been reported in pediatric patients. Especially, NIPE is expected to be useful for providing adequate analgesia in newborns and infants and children under 2 years of age under anesthesia or a conscious state. SCA may be best used to assess stress in conscious or sedated newborns and younger children, but there is still little evidence of the efficacy of the analgesia during general anesthesia in pediatric patients. Pupillometry has shown reliable results in pediatric patients under anesthesia, as in adults, but has some pitfalls, because the measurement may be inaccurate or complicated by a range of factors. It has been reported that ANI performs well compared to other devices on postoperative pain, but there are still suboptimal results. SPI, ANI, and pupillometry may be useful for evaluating the effects of regional analgesia performed during general anesthesia. In this situation, ANI also enables the optimization of opioid consumption.

A thorough understanding of the pros and cons of the nociception monitoring tools summarized above and their application in clinical situations will provide a more effective and safe intraoperative analgesia for pediatric patients undergoing general anesthesia, and it may also facilitate the planning and conduct of research on the use of intraoperative nociception monitoring in pediatric patients.

\section{SUPPLEMENTARY MATERIALS}

Supplementary data containing Korean version of this article is available at https://doi.org/10.17085/apm.2019.14.4.380.

\section{CONFLICTS OF INTEREST}

No potential conflict of interest relevant to this article was reported.

\section{REFERENCES}

1. Cowen R, Stasiowska MK, Laycock H, Bantel C. Assessing pain objectively: the use of physiological markers. Anaesthesia 2015; 70: 828-47.

2. Jiao Y, He B, Tong X, Xia R, Zhang C, Shi X. Intraoperative monitoring of nociception for opioid administration: a meta-analysis of randomized controlled trials. Minerva Anestesiol 2019; 85: 522-30. 
3. Tsuji H, Shirasaka C, Asoh T, Uchida I. Effects of epidural administration of local anaesthetics or morphine on postoperative nitrogen loss and catabolic hormones. Br J Surg 1987; 74: 421-5.

4. Kehlet H. Surgical stress: the role of pain and analgesia. Br J Anaesth 1989; 63: 189-95.

5. Wasylak TJ, Abbott FV, English MJ, Jeans ME. Reduction of postoperative morbidity following patient-controlled morphine. Can J Anaesth 1990; 37: 726-31.

6. Furuya K, Shimizu R, Hirabayashi Y, Ishii R, Fukuda H. Stress hormone responses to major intra-abdominal surgery during and immediately after sevoflurane-nitrous oxide anaesthesia in elderly patients. Can J Anaesth 1993; 40: 435-9.

7. Schricker T, Carli F, Schreiber M, Wachter U, Geisser W, Lattermann R, et al. Propofol/sufentanil anesthesia suppresses the metabolic and endocrine response during, not after, lower abdominal surgery. Anesth Analg 2000; 90: 450-5.

8. Benarroch EE. Pain-autonomic interactions. Neurol Sci 2006; 27 Suppl 2: S130-3.

9. Huiku M, Uutela K, van Gils M, Korhonen I, Kymäläinen M, Meriläinen $\mathrm{P}$, et al. Assessment of surgical stress during general anaesthesia. Br J Anaesth 2007; 98: 447-55.

10. Chen X, Thee C, Gruenewald M, Wnent J, Illies C, Hoecker J, et al. Comparison of surgical stress index-guided analgesia with standard clinical practice during routine general anesthesia: a pilot study. Anesthesiology 2010; 112: 1175-83.

11. Struys MM, Vanpeteghem C, Huiku M, Uutela K, Blyaert NB, Mortier EP. Changes in a surgical stress index in response to standardized pain stimuli during propofol-remifentanil infusion. Br J Anaesth 2007; 99: 359-67.

12. Bergmann I, Göhner A, Crozier TA, Hesjedal B, Wiese CH, Popov AF, et al. Surgical pleth index-guided remifentanil administration reduces remifentanil and propofol consumption and shortens recovery times in outpatient anaesthesia. Br J Anaesth 2013; 110: 622-8.

13. Won YJ, Lim BG, Lee SH, Park S, Kim H, Lee IO, et al. Comparison of relative oxycodone consumption in surgical pleth index-guided analgesia versus conventional analgesia during sevoflurane anesthesia: a randomized controlled trial. Medicine (Baltimore) 2016; 95: e4743.

14. Bapteste L, Szostek AS, Chassard D, Desgranges FP, Bouvet L. Can intraoperative Surgical Pleth Index values be predictive of acute postoperative pain? Anaesth Crit Care Pain Med 2019; 38: 391-2.

15. Bonhomme V, Uutela K, Hans G, Maquoi I, Born JD, Brichant JF, et al. Comparison of the surgical Pleth Index ${ }^{\mathrm{TM}}$ with haemodynamic variables to assess nociception-anti-nociception balance during general anaesthesia. Br J Anaesth 2011; 106: 101-11.
16. Colombo R, Raimondi F, Rech R, Castelli A, Fossali T, Marchi A, et al. Surgical Pleth Index guided analgesia blunts the intraoperative sympathetic response to laparoscopic cholecystectomy. Minerva Anestesiol 2015; 81: 837-45.

17. Jain N, Gera A, Sharma B, Sood J, Chugh P. Comparison of Surgical Pleth Index-guided analgesia using fentanyl versus conventional analgesia technique in laparoscopic cholecystectomy. Minerva Anestesiol 2019; 85: 358-65.

18. Gruenewald M, Willms S, Broch O, Kott M, Steinfath M, Bein B. Sufentanil administration guided by surgical pleth index vs standard practice during sevoflurane anaesthesia: a randomized controlled pilot study. Br J Anaesth 2014; 112: 898-905.

19. Park JH, Lim BG, Kim H, Lee IO, Kong MH, Kim NS. Comparison of Surgical Pleth Index-guided analgesia with conventional analgesia practices in children: a randomized controlled trial. Anesthesiology 2015; 122: 1280-7.

20. Ilies C, Ludwigs J, Gruenewald M, Thee C, Hanf J, Hanss R, et al. The effect of posture and anaesthetic technique on the surgical pleth index. Anaesthesia 2012; 67: 508-13.

21. Hans P, Verscheure S, Uutela K, Hans G, Bonhomme V. Effect of a fluid challenge on the Surgical Pleth Index during stable propofol-remifentanil anaesthesia. Acta Anaesthesiol Scand 2012; 56: 787-96.

22. Ilies C, Gruenewald M, Ludwigs J, Thee C, Höcker J, Hanss R, et al. Evaluation of the surgical stress index during spinal and general anaesthesia. Br J Anaesth 2010; 105: 533-7.

23. Ahonen J, Jokela R, Uutela K, Huiku M. Surgical stress index reflects surgical stress in gynaecological laparoscopic day-case surgery. Br J Anaesth 2007; 98: 456-61.

24. Ledowski T, Sommerfield D, Slevin L, Conrad J, von UngernSternberg BS. Surgical pleth index: prediction of postoperative pain in children? Br J Anaesth 2017; 119: 979-83.

25. Song IK, Ji SH, Kim EH, Lee JH, Kim JT, Kim HS. Comparison of the effect of different infusion rates of sufentanil on surgical stress index during cranial pinning in children under general anaesthesia: a randomized controlled study. BMC Anesthesiol 2017; 17: 167.

26. Harju J, Kalliomäki ML, Leppikangas H, Kiviharju M, Yli-Hankala A. Surgical pleth index in children younger than 24 months of age: a randomized double-blinded trial. Br J Anaesth 2016; 117: 358-64.

27. Sarkola T, Manlhiot C, Slorach C, Bradley TJ, Hui W, Mertens $\mathrm{L}$, et al. Evolution of the arterial structure and function from infancy to adolescence is related to anthropometric and blood pressure changes. Arterioscler Thromb Vasc Biol 2012; 32: 251624.

28. Dinenno FA, Dietz NM, Joyner MJ. Aging and forearm postjunc- 
tional alpha-adrenergic vasoconstriction in healthy men. Circulation 2002; 106: 1349-54.

29. Dorlas JC, Nijboer JA. Photo-electric plethysmography as a monitoring device in anaesthesia. Application and interpretation. Br J Anaesth 1985; 57: 524-30.

30. Mustola S, Parkkari T, Uutela K, Huiku M, Kymäläinen M, Toivonen J. Performance of surgical Stress Index during sevoflurane-fentanyl and isoflurane-fentanyl anesthesia. Anesthesiol Res Pract 2010; 2010: 810721.

31. Kallio H, Lindberg LI, Majander AS, Uutela KH, Niskanen ML, Paloheimo MP. Measurement of surgical stress in anaesthetized children. Br J Anaesth 2008; 101: 383-9.

32. Won YJ, Lim BG, Kim YS, Lee M, Kim H. Usefulness of surgical pleth index-guided analgesia during general anesthesia: a systematic review and meta-analysis of randomized controlled trials. J Int Med Res 2018; 46: 4386-98.

33. Koenig J, Jarczok MN, Ellis RJ, Hillecke TK, Thayer JF. Heart rate variability and experimentally induced pain in healthy adults: a systematic review. Eur J Pain 2014; 18: 301-14.

34. Task Force of The European Society of Cardiology and The North American Society of Pacing and Electrophysiology. Heart rate variability: standards of measurement, physiological interpretation and clinical use. Circulation 1996; 93: 1043-65.

35. Lindh V, Wiklund U, Håkansson S. Assessment of the effect of EMLA during venipuncture in the newborn by analysis of heart rate variability. Pain 2000; 86: 247-54.

36. Lindh V, Wiklund U, Sandman PO, Håkansson S. Assessment of acute pain in preterm infants by evaluation of facial expression and frequency domain analysis of heart rate variability. Early Hum Dev 1997; 48: 131-42.

37. Mazzeo AT, La Monaca E, Di Leo R, Vita G, Santamaria LB. Heart rate variability: a diagnostic and prognostic tool in anesthesia and intensive care. Acta Anaesthesiol Scand 2011; 55: 797-811.

38. Vigo DE, Guinjoan SM, Scaramal M, Siri LN, Cardinali DP. Wavelet transform shows age-related changes of heart rate variability within independent frequency components. Auton Neurosci 2005; 123: 94-100.

39. Elghozi JL, Girard A, Laude D. Effects of drugs on the autonomic control of short-term heart rate variability. Auton Neurosci 2001; 90: 116-21.

40. Pignotti M, Steinberg M. Heart rate variability as an outcome measure for Thought Field Therapy in clinical practice. J Clin Psychol 2001; 57: 1193-206.

41. Williams DP, Chelimsky G, McCabe NP, Koenig J, Singh P, Janata J, et al. Effects of chronic pelvic pain on heart rate variability in women. J Urol 2015; 194: 1289-94.
42. Polster A, Friberg P, Gunterberg V, Öhman L, Le Nevé B, Törnblom $\mathrm{H}$, et al. Heart rate variability characteristics of patients with irritable bowel syndrome and associations with symptoms. Neurogastroenterol Motil 2018; 30: e13320.

43. Kato M, Komatsu T, Kimura T, Sugiyama F, Nakashima K, Shimada Y. Spectral analysis of heart rate variability during isoflurane anesthesia. Anesthesiology 1992; 77: 669-74.

44. Unoki T, Grap MJ, Sessler CN, Best AM, Wetzel P, Hamilton A, et al. Autonomic nervous system function and depth of sedation in adults receiving mechanical ventilation. Am J Crit Care 2009; 18: 42-50.

45. Latson TW, O'Flaherty D. Effects of surgical stimulation on autonomic reflex function: assessment by changes in heart rate variability. Br J Anaesth 1993; 70: 301-5.

46. Jeanne M, Logier R, De Jonckheere J, Tavernier B. Validation of a graphic measurement of heart rate variability to assess analgesia/nociception balance during general anesthesia. Conf Proc IEEE Eng Med Biol Soc 2009; 2009: 1840-3.

47. Jeanne M, Logier R, De Jonckheere J, Tavernier B. Heart rate variability during total intravenous anesthesia: effects of nociception and analgesia. Auton Neurosci 2009; 147: 91-6.

48. Chang LH, Ma TC, Tsay SL, Jong GP. Relationships between pain intensity and heart rate variability in patients after abdominal surgery: a pilot study. Chin Med J (Engl) 2012; 125: 1964-9.

49. Meeuse JJ, Löwik MS, Löwik SA, Aarden E, van Roon AM, Gans $\mathrm{RO}$, et al. Heart rate variability parameters do not correlate with pain intensity in healthy volunteers. Pain Med 2013; 14: 1192201.

50. De Jonckheere J, Rakza T, Logier R, Jeanne M, Jounwaz R, Storme L. Heart rate variability analysis for newborn infants prolonged pain assessment. Conf Proc IEEE Eng Med Biol Soc 2011; 2011: 7747-50.

51. Hummel P, van Dijk M. Pain assessment: current status and challenges. Semin Fetal Neonatal Med 2006; 11: 237-45.

52. Faye PM, De Jonckheere J, Logier R, Kuissi E, Jeanne M, Rakza T, et al. Newborn infant pain assessment using heart rate variability analysis. Clin J Pain 2010; 26: 777-82.

53. Waxman JA, Pillai Riddell RR, Tablon P, Schmidt LA, Pinhasov A. Development of cardiovascular indices of acute pain responding in infants: a systematic review. Pain Res Manag 2016; 2016: 8458696.

54. Janda M, Bajorat J, Kudlik C, Pohl B, Schubert A, NöldgeSchomburg G, et al. Comparison of heart rate variability response in children undergoing elective endotracheal intubation with and without neuromuscular blockade: a randomized controlled trial. Paediatr Anaesth 2013; 23: 1153-9.

55. Toweill DL, Kovarik WD, Carr R, Kaplan D, Lai S, Bratton S, et 
al. Linear and nonlinear analysis of heart rate variability during propofol anesthesia for short-duration procedures in children. Pediatr Crit Care Med 2003; 4: 308-14.

56. Upton HD, Ludbrook GL, Wing A, Sleigh JW. Intraoperative "Analgesia Nociception Index"-guided fentanyl administration during sevoflurane anesthesia in lumbar discectomy and laminectomy: a randomized clinical trial. Anesth Analg 2017; 125: 81-90.

57. Szental JA, Webb A, Weeraratne C, Campbell A, Sivakumar H, Leong S. Postoperative pain after laparoscopic cholecystectomy is not reduced by intraoperative analgesia guided by analgesia nociception index $\left(\mathrm{ANI}^{\circledR}\right)$ monitoring: a randomized clinical trial. Br J Anaesth 2015; 114: 640-5.

58. Gruenewald M, Herz J, Schoenherr T, Thee C, Steinfath M, Bein B. Measurement of the nociceptive balance by Analgesia Nociception Index and Surgical Pleth Index during sevofluraneremifentanil anesthesia. Minerva Anestesiol 2015; 81: 480-9.

59. Jeanne M, Clément C, De Jonckheere J, Logier R, Tavernier B. Variations of the analgesia nociception index during general anaesthesia for laparoscopic abdominal surgery. J Clin Monit Comput 2012; 26: 289-94.

60. Julien-Marsollier F, Rachdi K, Caballero MJ, Ayanmanesh F, Vacher T, Horlin AL, et al. Evaluation of the analgesia nociception index for monitoring intraoperative analgesia in children. Br J Anaesth 2018; 121: 462-8.

61. Sabourdin N, Arnaout M, Louvet N, Guye ML, Piana F, Constant I. Pain monitoring in anesthetized children: first assessment of skin conductance and analgesia-nociception index at different infusion rates of remifentanil. Paediatr Anaesth 2013; 23: 14955.

62. Weber F, Geerts NJE, Roeleveld HG, Warmenhoven AT, Liebrand CA. The predictive value of the heart rate variabilityderived Analgesia Nociception Index in children anaesthetized with sevoflurane: an observational pilot study. Eur J Pain 2018; 22: 1597-605.

63. Boselli E, Daniela-Ionescu M, Bégou G, Bouvet L, Dabouz R, Magnin C, et al. Prospective observational study of the noninvasive assessment of immediate postoperative pain using the analgesia/nociception index (ANI). Br J Anaesth 2013; 111: 4539.

64. Boselli E, Bouvet L, Bégou G, Dabouz R, Davidson J, Deloste JY, et al. Prediction of immediate postoperative pain using the analgesia/nociception index: a prospective observational study. Br J Anaesth 2014; 112: 715-21.

65. Ledowski T, Tiong WS, Lee C, Wong B, Fiori T, Parker N. Analgesia nociception index: evaluation as a new parameter for acute postoperative pain. Br J Anaesth 2013; 111: 627-9.
66. Brouse CJ, Karlen W, Myers D, Cooke E, Stinson J, Lim J, et al. Wavelet transform cardiorespiratory coherence detects patient movement during general anesthesia. Conf Proc IEEE Eng Med Biol Soc 2011; 2011: 6114-7.

67. Brouse CJ, Karlen W, Dumont GA, Myers D, Cooke E, Stinson $\mathrm{J}$, et al. Real-time cardiorespiratory coherence detects antinociception during general anesthesia. Conf Proc IEEE Eng Med Biol Soc 2012; 2012: 3813-6.

68. Brouse CJ, Karlen W, Dumont GA, Myers D, Cooke E, Stinson J, et al. Monitoring nociception during general anesthesia with cardiorespiratory coherence. J Clin Monit Comput 2013; 27: 551-60.

69. Butruille L, De jonckheere J, Marcilly R, Boog C, da Costa SB, Rakza T, et al. Development of a pain monitoring device focused on newborn infant applications: the NeoDoloris project. IRBM 2015; 36: 80-5.

70. Weber F, Roeleveld HG, Geerts NJE, Warmenhoven AT, Schröder R, de Leeuw TG. The heart rate variability-derived Newborn Infant Parasympathetic Evaluation $\left(\mathrm{NIPE}^{\mathrm{TM}}\right)$ Index in pediatric surgical patients from 0 to 2 years under sevoflurane anesthesia-a prospective observational pilot study. Paediatr Anaesth 2019; 29: 377-84.

71. Zhang K, Wang S, Wu L, Song Y, Cai M, Zhang M, et al. Newborn infant parasympathetic evaluation (NIPE) as a predictor of hemodynamic response in children younger than 2 years under general anesthesia: an observational pilot study. BMC Anesthesiol 2019; 19: 98

72. Valencia-Ramos J, Arnaez J, Calvo S, Gomez F, Del Blanco I. Observational study of newborn infant parasympathetic evaluation as a comfort system in awake patients admitted to a pediatric intensive care unit. J Clin Monit Comput 2019; 33: 749-55.

73. Cremillieux C, Makhlouf A, Pichot V, Trombert B, Patural H. Objective assessment of induced acute pain in neonatology with the Newborn Infant Parasympathetic Evaluation index. Eur J Pain 2018; 22: 1071-9.

74. Lidberg L, Wallin BG. Sympathetic skin nerve discharges in relation to amplitude of skin resistance responses. Psychophysiology 1981; 18: 268-70.

75. Bini G, Hagbarth KE, Hynninen P, Wallin BG. Thermoregulatory and rhythm-generating mechanisms governing the sudomotor and vasoconstrictor outflow in human cutaneous nerves. J Physiol 1980; 306: 537-52.

76. Storm H. Changes in skin conductance as a tool to monitor nociceptive stimulation and pain. Curr Opin Anaesthesiol 2008; 21: 796-804.

77. Storm H. Skin conductance and the stress response from heel stick in preterm infants. Arch Dis Child Fetal Neonatal Ed 2000; 
83: F143-7.

78. Hellerud BC, Storm H. Skin conductance and behaviour during sensory stimulation of preterm and term infants. Early Hum Dev 2002; 70: 35-46.

79. Salavitabar A, Haidet KK, Adkins CS, Susman EJ, Palmer C, Storm H. Preterm infants' sympathetic arousal and associated behavioral responses to sound stimuli in the neonatal intensive care unit. Adv Neonatal Care 2010; 10: 158-66.

80. Scaramuzzo RT, Faraoni M, Polica E, Pagani V, Vagli E, Boldrini A. Skin conductance variations compared to $\mathrm{ABC}$ scale for pain evaluation in newborns. J Matern Fetal Neonatal Med 2013; 26: 1399-403.

81. Gjerstad AC, Wagner K, Henrichsen T, Storm H. Skin conductance versus the modified COMFORT sedation score as a measure of discomfort in artificially ventilated children. Pediatrics 2008; 122: e848-53.

82. Storm H, Myre K, Rostrup M, Stokland O, Lien MD, Raeder JC. Skin conductance correlates with perioperative stress. Acta Anaesthesiol Scand 2002; 46: 887-95.

83. Gjerstad AC, Storm H, Hagen R, Huiku M, Qvigstad E, Raeder J. Comparison of skin conductance with entropy during intubation, tetanic stimulation and emergence from general anaesthesia. Acta Anaesthesiol Scand 2007; 51: 8-15.

84. Ledowski T, Bromilow J, Wu J, Paech MJ, Storm H, Schug SA. The assessment of postoperative pain by monitoring skin conductance: results of a prospective study. Anaesthesia 2007; 62: 989-93.

85. Ledowski T, Bromilow J, Paech MJ, Storm H, Hacking R, Schug SA. Monitoring of skin conductance to assess postoperative pain intensity. Br J Anaesth 2006; 97: 862-5.

86. Sabourdin N, Giral T, Wolk R, Louvet N, Constant I. Pupillary reflex dilation in response to incremental nociceptive stimuli in patients receiving intravenous ketamine. J Clin Monit Comput 2018; 32: 921-8.

87. Constant I, Nghe MC, Boudet L, Berniere J, Schrayer S, Seeman $\mathrm{R}$, et al. Reflex pupillary dilatation in response to skin incision and alfentanil in children anaesthetized with sevoflurane: a more sensitive measure of noxious stimulation than the commonly used variables. Br J Anaesth 2006; 96: 614-9.

88. Connelly MA, Brown JT, Kearns GL, Anderson RA, St Peter SD, Neville KA. Pupillometry: a non-invasive technique for pain assessment in paediatric patients. Arch Dis Child 2014; 99: 112531.

89. Sabourdin N, Peretout JB, Khalil E, Guye ML, Louvet N, Constant I. Influence of depth of hypnosis on pupillary reactivity to a standardized tetanic stimulus in patients under propofol- remifentanil target-controlled infusion: a crossover randomized pilot study. Anesth Analg 2018; 126: 70-7.

90. Bertrand AL, Garcia JB, Viera EB, Santos AM, Bertrand RH. Pupillometry: the influence of gender and anxiety on the pain response. Pain Physician 2013; 16: E257-66.

91. Larson MD. The effect of antiemetics on pupillary reflex dilation during epidural/general anesthesia. Anesth Analg 2003; 97: 1652-6.

92. Larson MD, Talke PO. Effect of dexmedetomidine, an alpha2adrenoceptor agonist, on human pupillary reflexes during general anaesthesia. Br J Clin Pharmacol 2001; 51: 27-33.

93. Migeon A, Desgranges FP, Chassard D, Blaise BJ, De Queiroz M, Stewart A, et al. Pupillary reflex dilatation and analgesia nociception index monitoring to assess the effectiveness of regional anesthesia in children anesthetised with sevoflurane. Paediatr Anaesth 2013; 23: 1160-5.

94. Raof RA, El Metainy SA, Alia DA, Wahab MA. Dexmedetomidine decreases the required amount of bupivacaine for ultrasound-guided transversus abdominis plane block in pediatrics patients: a randomized study. J Clin Anesth 2017; 37: 55-60.

95. Ecoffey C, Lacroix F, Giaufré E, Orliaguet G, Courrèges P; Association des Anesthésistes Réanimateurs Pédiatriques d'Expression Française (ADARPEF). Epidemiology and morbidity of regional anesthesia in children: a follow-up one-year prospective survey of the French-Language Society of Paediatric Anaesthesiologists (ADARPEF). Paediatr Anaesth 2010; 20: 1061-9.

96. Oberndorfer U, Marhofer P, Bösenberg A, Willschke H, Felfernig M, Weintraud M, et al. Ultrasonographic guidance for sciatic and femoral nerve blocks in children. Br J Anaesth 2007; 98: 797-801.

97. Chhabra A, Sinha R, Subramaniam R, Chandra P, Narang D, Garg SP. Comparison of sub-Tenon's block with i.v. fentanyl for paediatric vitreoretinal surgery. Br J Anaesth 2009; 103: 739-43.

98. Naja Z, Al-Tannir MA, Faysal W, Daoud N, Ziade F, El-Rajab M. A comparison of pudendal block vs dorsal penile nerve block for circumcision in children: a randomised controlled trial. Anaesthesia 2011; 66: 802-7.

99. Song IK, Ji SH, Kim EH, Lee JH, Kim JT, Kim HS. Heart rate variability may be more useful than pulse transit time for confirming successful caudal block under general anesthesia in children. Anesth Pain Med 2017; 12: 140-6.

100. Dundar N, Kus A, Gurkan Y, Toker K, Solak M. Analgesia nociception index (ani) monitoring in patients with thoracic paravertebral block: a randomized controlled study. J Clin Monit Comput 2018; 32: 481-6. 